\title{
Pengembangan Algoritma Pembelajaran untuk Jaringan Syaraf Tiruan Diagonal Recurrent dalam Sistem Kendali Derau Akustik Secara Aktif
}

\author{
Bomo Wibowo Sanjaya), Redi Ratiandi Yacoub ${ }^{2)}$ \\ Dosen Jurusan Teknik Elektro Fakultas Teknik Universitas Tanjungpura \\ Email: bomowibowo@yahoo.com ${ }^{1)}$, rediry@yahoo.com ${ }^{2)}$
}

\begin{abstract}
ABSTRAK
Sistem kendali derau aktif lebih menitikberatkan pada penggunaan algoritma adaptasi dan stukktrkendali adaptif Dalam penelitian ini ditampilkan hasil percobaan sistem kendali derau aktif pada ruang terbuka menggunakan stukturkendali Jaringan Syaraf Tiruan Diagonal Recurrent (JSTDR). Pengembangan algoritma Extended Kalman Filter (EKF)untuk struktur kendali JSTDR, yang kemudian dinamakan sebagai algoritma Extended Kalman Filter Diagonal Reaurrent (EKFDR) merupakan tujuan dari penelitian ini. Masalah nonlinieritas jalur sekunder dalam sistem kendali deaa aktif dapat mempersulit proses pengendalian. Dari hasil percobaan terlihat bahwa jumlah neuron dalam JST dapat dikurangi dengan menggunakan JSTDR, tanpa mengurangi kinerja sistem kendali. JSTDR dengan algoritmaEKFDR jugamenunjukkan kinerja yang baik dalam mengkompensasi nonlinieritas jalur sekunder jika dibandingkan dengan pengendali linie.
\end{abstract}

Kata kunci: derau aktif, jaringan syaraf tiruan, diagonal recurrent, extended kalman filterdiagonal reaurrent, nonlinieitas jalur sekunder.

\begin{abstract}
Active Noise Control (ANC) system emphasizes at usage of adaptation algorithm and adaptivecontrol structure. In this research is presented experimental result of active noise control system at free space using Diagonal Reaurrent Antifiaal Neural Network control structure. The objective of this research is to develop an Extended Kalman Filter (EKF)algorithm for Diagonal Recurrent Artificial Neural Network control structure, named as Extended Kalman Filter Diagonal Reaurrent (EKFDR) algorithm. Experimental result shows that amount of neuron in artifial neural networkcan be reduced by using diagonal recurrent artificial neural network, without lessening control systemperformance. Nonlinearity of secondarypath in active noise control system can complicate control process. Experimental result shows that diagonal reaurrent artifial neural network with EKFDR algorithm produced a better performance than linear controller in compensating of secondary path nonlinearity.
\end{abstract}

Keywords: active noise, neural network, diagonal recurrent, extended kalman filter diagonal reaurrent, secondarypath nonlinearity.

\section{PENDAHULUAN}

\section{Latar Belakang}

Pendekatan tradisional untuk meredam derauakustik dilakukan dengan menggunakan material-material peredam tertentu, seperti dinding pemisah (enclosure), penghalang (bamier), maupun penyerap suara (silencers). Bahan atau material tersebut ditempatkan di sekitar sumber derau atau di ruang yang intensitas deraunya hendak dikurangi. Teknik peredaman seperti ini dikenal sebagai kendali derau dengan teknik pasif. Teknik pasif padaumumnya efektif untuk derau berfrekuensi tinggi. Peredam pasif menghasilkan peredaman yang kecil ketika panjang gelombang akustiknya cukup besar dibandingkan

Catatan: Diskusi untuk makalah ini diterima sebelum tanggal 1 Juni 2007. Diskusi y ang layak muat akan diterbitkan pada Jurnal Teknik Elektro volume 7, nom or 1, September 2007. dengan dimensi peredam, seperti panjang atau ketebalan dinding, dan seringkali menimbulkan tekanan balik. Untuk meredam derau berfrekuensi rendah akan dibutuhkan bahan peredam yangtebal, berat, dan dengan harga yang relatif mahal. Sehingga teknik pasif tidak efektif untuk derau berfrekuensi rendah. Derau frekuensi rendah diketahuitidak hanya mengganggu untuk jangka waktu panjang, namun juga menimbulkan kelelahan dan hilangnya konsentrasi manusia, yang mengakibatkan berkurangnya produktivitas. Untuk memecahkan masalah ini maka digunakan sistem kendali derau dengan teknik aktif, atau lebih dikenal dengan sistem kendaliderauaktif (Active Noise Control, ANC). Sistem ANCmenggunakan sumber sekunder untuk menghilangkan derau dari sumber primer.

Sistem ANC secara efisien meredam derau frekuensi rendah dimana pada jangkauan ini metodapasif sudah tidak efektif. ANC menjanjikan peningkatan dalam 
kualitas kendali derau, baik keuntungan potensial dari segi ukuran, berat, volume maupun biaya[1]. ANC sejak lama didemonstrasikan di laboratorium riset, tetapi sekarang telah dikembangkan dalam banyak aplikasi industri komersil. Situasi berubah dengan cepat, ANC mempunyai dampak yangbesar dalam mengurangi derau, terutama menjadi semakin ekonomis dan efektif untuk mengurangi derau frekuensi rendah. Sistem ANClebih menitikberatkan dalam penggunaan algoritma adaptasi dan struktur pengolahan sinyal secara adaptif berdasarkan masukan-masukan dari sensor-sensor yangdigunakan, yang bertujuan untuk meminimumkan suatu kriteria tertentu.

Akhir-akhir ini banyak implementasi ANCmenggunakan teknik pemfilteran linier adaptif. Bentuk yang paling banyak dikenal dari kombinasi arsitektur/algoritma adaptif berdasarkan pendekatan linier adalah pengendali berbasis filter tranversal, seperti Filter FIR (Finite Impulse Response) atau Filter IIR (Infinite Impulse Response) yang diadaptasi dengan memakai algoritma Filt ered-X Least-MeanSquares (FX-LMS) [2].

Pengendali digital linier ini belum memberikan kinerja yang baik, terutama pada kasus dimana ketaklinearan ditemukan dalam sistem ANC. Sumber ketaklinearan yang umum adalah aktuator. Suatu aktuator secara khas mempunyai tanggapan nonlinear ketika beroperasi dengan suatu sinyal masukan yang mempunyai amplitudo mendekati atau di atasnilai sinyal masukan nominal, at auketika beroperasi pach suatu frekuensi di luar rentang frekuensi nominal. Perilaku nonlinier dapat juga terjadi ketika dinamika sistem yang akan dikendalikan nonlinear [2].

Pengunaan struktur kendali Jaringan Syaraf Tinuan (JST) dengan algoritma nonlinier adaptif merupakan salah satu solusi untuk mengatasi masalah ini.

\section{Perumusan Permasalahan}

Dalam implementasi dengan menggunakan struktur kendali Jaringan Syaraf Tiruan (JST) dengan algoritma nonlinier adapt if sering ditemui masalah komputasi. Komputasi yang terlalu berat dapat menyebabkan masalah real-time. Untuk itu diperlukan struktur JST diagonal recurrent yangdapat mengurangi jumlah layer yang digunakan sehingga mengurangi waktu komputasi.

\section{Tujuan Penelitian}

Penelitian ini bertujuan mendapatkan algoritma pembelajaran nonlinier adapt if untuk jaringan syaraf tiruan diagonal recurrent dalam sistem kendali derau akustik secara aktif sehingga dapat mengkompensasi non-linieritas sistem dan dapat mengurangi beban komputasi selama proses kendali berlangsung.

\section{Manfaat Penelitian}

Penelitian ini merupakan penyempurnaan dari hasil penelitian di bidang ANC yang telah dilakukan sebelumnya. Hasil penelitian menunjukkan sistem kendali derau akustik secara aktif dengan algoritma pembelajaran nonlinier adaptif untuk jaringan syaraf tiruan diagonal recurrent dapat mengkompensasi non-linieritas sistem dan dapat mengurangibeban komputasi selama proses kendali sehingga dapat digunakan sebagai pengendali derau akustik yang menggunakan peralatan yang lebih sederhana. Selain itu juga dimungkinkan untuk digunakan pada sistem multi kanal yang mempunyai beban komputasi yang lebih berat.

\section{TINJAUAN PUSTAKA}

\section{Konsep Fisik Peredaman Derau Secara Aktif}

Peredaman derau secara aktif mengacupada prinsip superposisi destruktif. Suatu sinyal anti derau(dengan amplitudo yang sama dan fasa yang berlawanan dengan sinyal derau primer) dibangkitkan dan dikombinasikan dengan sinyal derau primer, yang kemudian menghasilkan efek salingmenghilangkan pada kedua sinyal tersebut. Tingkat penghilangan sinyal derau primer tergantung pada akurasi amplitudo dan fasa dari sinyal anti derau yang dibangkitkan[1]. Konsep fisik dariperedaman sinyal derau secara aktif diilustrasikan dalam Gambar 1.

Ditinjau dari daerah jangkauan frekuensinya, derau dapat dikelompokkan [1]

a. Derau pita lebar (broadband noise).

Derau pita lebar ditandai dengan tersebarnya energi akustik di banyak tempat dalam daerah frekuensi. Salah satu sebab derau jenis ini adalah gejala turbulensi yang bersifat acak, misalnya bunyi frekuensi rendah pesawat jet dan impuls ledakan. Untuk peredaman deraupita lebar, sinyal masukan referensi harus memberikan petunjuk pendahulu yang cukup tentang derau. Iniberarti sinyal acuan harus menyerupai sinyal derauutama. Salah satu caranya adalah dengan menempatkan sensor acuan sedekat mungkin dengan sumber derau. Dengan demikian sinyal acuan yang berkorelasi dengan derau utama dapat diperoleh, dan digunakan untuk membangkitkan sinyal anti derau yang dapat meredam derau di sekitar sumber sekunder. 
b. Derau pita sempit (narrowband noise).

Derau pita sempit hanya memperlihatkan konsentrasi energi di tempat tertentusaja dalam daerah frekuensi. Derau jenis ini dapat berasal dari gejala mekanik yang berulang, seperti halnya putaran as dari mesin yang frekuensinya hampir periodik. Mesin internal combustion, turbin dan compressor adalah contoh sumber derau pita sempit.

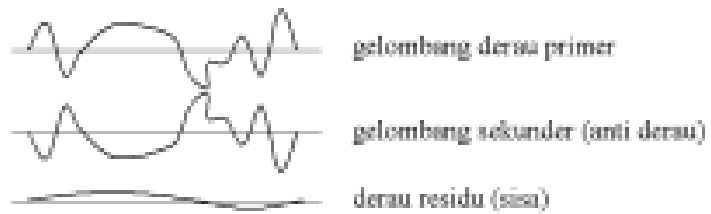

Gambar 1. Konsep Fisik dari Peredaman Sinyal Derau Secara Aktif.

\section{Tinjauan Umum Sistem Ken dali Derau aktif.}

Ditinjau dari penempatan sensor referensi, sistem kendali derau aktif diklasifikasikan ke dalam dua struktur[1]

a. Struktur umpanmaju, dimana pengukuran sinyal derau pada posisi sangat dekat dengan sumber derau.

b. Struktur umpanbalik, dimana pengukuran sinyal derau pada posisi setelah sumber sekunder.

Sistem kendali derau aktif umpanmaju(feedforward ANC systems) menggunakan sinyal referensi untuk membangkitkan sinyal kendali. Kemudian sinyal kendali disalurkan ke aktuator (loadspeaker) untuk menghasilkan sinyal anti derau (dengan amplitudb yang sama dan fasa yang berlawanan dengan sinyal derau primer) dalam ruang akustik, sehingga sinyal anti derau dapat meredam sinyal derauprimer yang tidak diinginkan. Struktur sistem kendaliderauaktif umpanmaju dalam ruang terbuka diperlihatkan dalam Gambar 2.

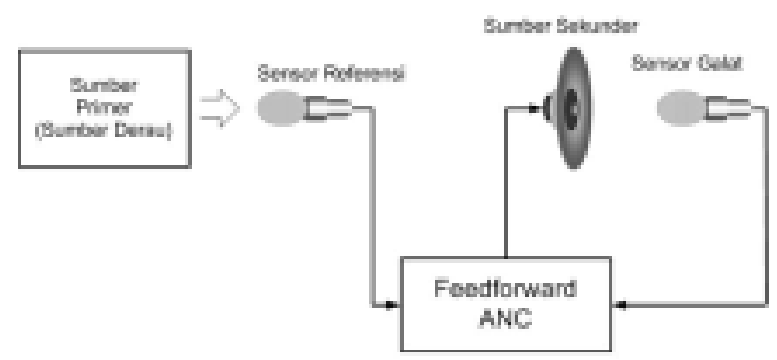

Gambar 2. Sistem ANC umpanmaju.

Sensor referensi (reference microphone) yangdekat dengan sumber derau, menangkap sinyal derau primer yang tidak diinginkan. Sensor galat (error microphone) menangkap sisa derau primer (sinyal residu) yang akan diminimisasi dan digunakan untuk mengadaptasi bobot-bobot dari pengendali.

Ditinjau dari jumlah kanal kendali yang tersedia, sistem kendali derau aktif diklasifikasikan[1]

a. Sistem kanal tunggal (single-channel ANC) Sistem kanal tunggal dibentuk oleh satu sensor acuan, satu sumber sekunder, dan satu sensor galat. Meski sederhana, sistem ini cukup efektif untuk mengurangi bising dalam media satu dimensi, seperti halnya bising dalam saluran udara.

b. Sistem multi kanal (multi-channel ANC) Sistem multi kanal terdiri dari sejumlah sensor acuan, sumber sekunder dan sensor galat, yang diatur dalam susunan tertentu. Sistem kendali derau aktif umpan maju multi kanal diperlihatkan dalam Gambar 3.

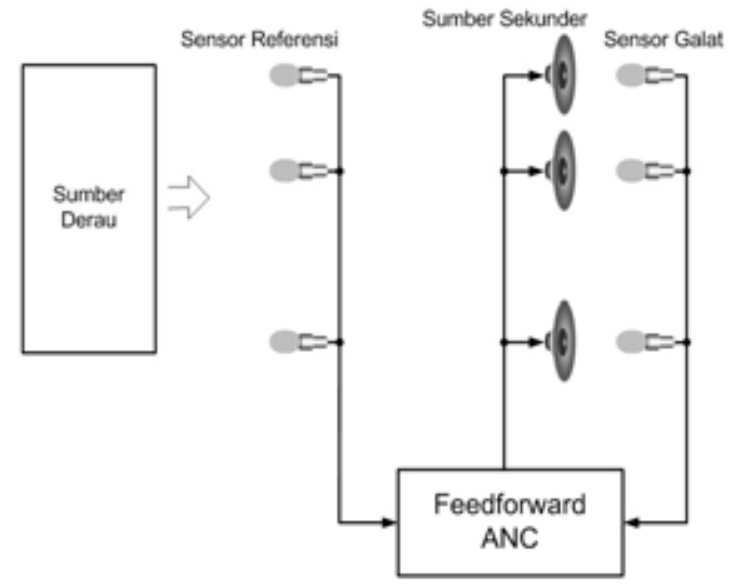

Gambar 3. Sistem ANC umpan majumultikanal

\section{Efek Jalur Sekunder}

Jalur sekunder dalam sistem kendali derau aktif diperlihatkan dalam Gambar 4.

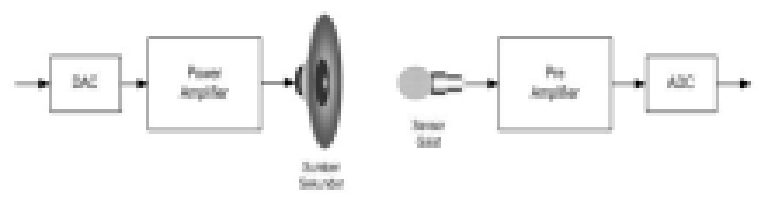

Gambar 4. Jalur sekunder dalam sistem ANC.

Sinyal sisa derau elektrik diperoleh dari sinyal sisa derau akustik dengan menggunakan sensor galat (error microphone). Sinyal kendali atausinyal anti derau diperoleh dari sinyal keluaran elektrik yang melalui aktuator sumber sekunder (canceling loudspeaker). Oleh karena itu, sejumlah fungsi alih harus dimasukkan untuk mengkompensasi hal-hal tersebut[1]. 


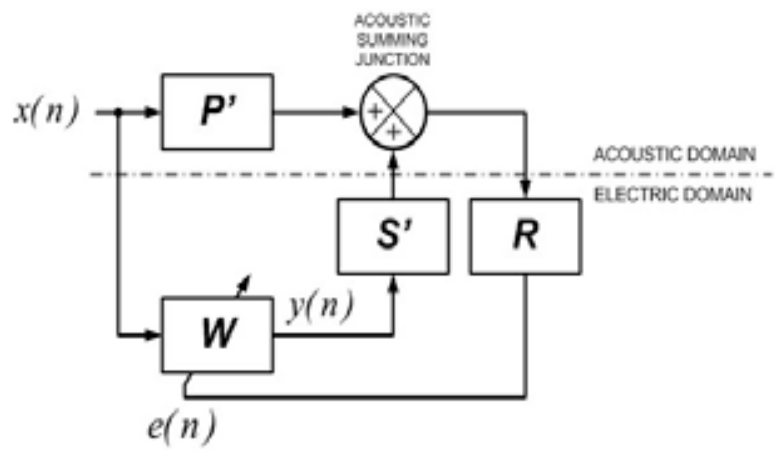

Gambar 5. Blok diagram efek jalur sekunder dalam sistem ANC.

Blok diagram efek jalur sekunder dalam implementasi sistem ANC diperlihatkan dalam Gambar 5. Pada Gambar 5, Acoustic summing junction merepresentasikan superposisi akustik dari keluaran aktuator sumber sekunder dan sinyal derau primer yang diterima oleh sensor galat.

Fungsi alih jalur primer $\boldsymbol{P}$ darireferencemicrophone ke error microphone dapat juga dipisahkan sebagai $\boldsymbol{P}=\boldsymbol{P}^{\prime} . \boldsymbol{R}$. Dimana $\boldsymbol{P}^{\prime}$ merepresentasikan fungsi alih dari sistem akustik yang tidak diketahui (dari reference microphone ke junction penjumlah akustik).

Fungsi alih jalur sekunder $\boldsymbol{S}$ dapat dipisahkan ke dalam fungsi alih dua kaskade, yaitu: $\boldsymbol{S}=\boldsymbol{S}^{\prime} . \boldsymbol{R} . \boldsymbol{S}^{\prime}$ merepresentasikan sistem DAC, power amplifier, loudspeaker, dan jalur akust ik antara loudspeakerke junction penjumlah. $\boldsymbol{R}$ merepresentasikan fungsi alih dari sistem error microphone, pre-amplifier, dan ADC. Identifikasi jalur sekunder, dilakukan dengan tujuan untuk mendapatkan model jalur sekunder $\boldsymbol{S}$ yang representatif, kemudian model jalur sekunder $\boldsymbol{S}$ diikutsertakan dalam penurunan algoritma adaptasi untuk pengendali (untuk propaasi balik sinyal resid ke jaringan pengendali). Blok diagram efek jalur sekunder yg disederhanakan diperlihatkan dalam Gambar 6.

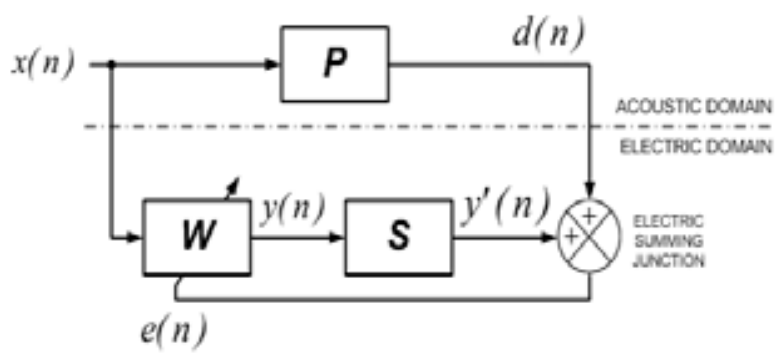

Gambar 6.Blok diagram efek jalur sekunder yang disederhanakan.
Komputasi Maju JST Dalam Sistem ANC.

Persamaan komputasi maju untuk JST umpan maju dari jaringan pengendali dirumuskan dalam Persamaan (1)-(3)[2][3].

Jika sensor referensi sebanyak $i$ dan $x_{i}(n-l)$ sinyal yang ditangkap oleh sensor referensi ke-i pada saat $n$ l, maka masukan JST umpan maju dirumuskan

$y_{i\left(L_{1}+1\right)+l}^{0}(n)=x_{i}(n-l) 0 \leq l \leq L_{1}, 0 \leq i \leq I-1$

dimana, $L_{1}$ menyatakan jumlah elemen dalam vektor masukan ke-i.

Untuk layer ke- $m$ yang mempunyai neuron sebanyak $j$, matrik bobot masukan pada saat $n$ dinyatakan sebagai $w_{i j}^{m}(n)$, maka nilai neuron ke-j dalam layer ke- $m$ dirumuskan

$s_{j}^{m}(n)=\sum_{i} w_{i j}^{m}(n) y_{i}^{m-1}(n)$

Tiap-tiap neuron dalam layer ke-m mempunyai fungsi alih nonlinier. Keluaran dari layerke-m pada saat $n$ dirumuskan

$y_{j}^{m}(n)=f\left(s_{j}^{m}(n)\right), \leq m \leq M+1$

Persamaan komputasi maju untuk JST umpan maju dari jaringan model jalur sekunder dirumuskan dalam Persamaan (4)-(7).

Jika pengendali mempunyai keluaran sebanyak $i$ dan $y_{i}(n-l)$ adalah sinyal kendali yang akan dikirim melalui jalur sekunder unt uk menghasilkan sinyal anti derau, maka nilai neuron ke- $j$ dalam layerpertama dari jaringan model jalur sekunder dirumuskan

$t_{j}^{1}(n)=\sum_{i} \sum_{l=0}^{L_{2}} h_{i, j, l}^{1} y_{i}(n-l)$

dengan $h_{i, j, l}^{1}$ nilai bobot neuron ke-j dalam layer pertama dari jaringan model jalur sekunder. Nilai bobot ini sudah diperoleh sebelumnya (hasilidentifikasi jalur sekunder).

Keluaran layer pertama dari jaringan model jalur sekunder pada saat $n$ dirumuskan

$z_{j}^{1}(n)=f\left(t_{j}^{1}(n)\right)$

nilai neuron ke-j dalam layer ke-p dari jaringan model jalur sekunder dirumuskan

$t_{j}^{p}(n)=\sum_{i} h_{i j}^{p}(n) z_{i}^{p}(n-l)$

dengan $h_{i, j, l}^{p}$ nilai bobot neuron ke-jdalam layerke$p$ dari jaringan model jalur sekunder. Nilai bobot ini sudah diperoleh sebelumnya (hasil identifikasi jalur sekunder). 
Keluaran dari layer ke- $p$ dari jaringan modeljalur sekunder pada saat $n$ dirumuskan:

$z_{j}^{p}(n)=f\left(t_{j}^{p}(n)\right), 2 \leq p \leq P+1$

Dalam junction penjumlah akustik, terjadi superposisi antara sinyal derau dengan sinyal anti derauyang dihasilkan oleh sumber sekunder, sehingga terjadi efek saling meniadakan. Sinyal derau hasil superposisi kedua sinyal tersebut dinamakan sinyal residu. Persamaan sinyal residu dirumuskan

$e_{k}(n)=d_{k}(n)+z_{k}^{p+1}(n)$

\section{Struktur JST Diagonal Recurrent}

Jaringan syaraf tiruan (JST) recurrent secara umum merupakan JST dua layer dengan umpanbalik dari keluaran layer pertama ke masukan layerpertama. Layer pertama adalah hidden (recurrent) layeryang tersusun atas neuron-neuron dengan fungsi alih nonlinier. Layer kedua adalah output-layer yang tersusun atas neuron-neuron dengan fungsi alih linier. Delay dalam koneksi recumentmenyimpan nilai-nilai (informasi) dari step waktu sebelumnya, yangdapat digunakan pada step waktu sekarang Hal ini menyebabkan JST recurrent mampu untuk mempelajari pola temporal. JST recurrent tidak memerlukan umpan balik eksternal yang melalui tapped-delayline.

Neuron self-recurrent adalah neuron yang mempunyai umpan balik dari keluaran neuron itusendiri. JST recurrent yang tersusun atasneuron-neuron selfrecurrent, dinamakan sebagai JST diagonal recument (JSTDR). Jika dibadingkan dengan JST fullyconected recurrent, struktur JST DR lebih sederhana dan jumlah bobot yang digunakan lebih sedikit, sehingga beban komputasi menjadi lebih ringan.

Struktur JST DR secara umum terdiri dari dua layer. Layer pertama adalah hidden (recurrent) layer, yang mempunyai neuron-neuron dengan fungsi alih nonlinier. Layer kedua adalah output layer, yang mempunyai neuron-neuron dengan fungsi alih linier. Struktur JST DR diperlihatkan dalam Gambar 7.

Jika sensor referensi sebanyak $i$ dan $x_{i}(n)$ sinyal yang ditangkap oleh sensor referensi ke-i pada saat $n$, maka masukan JST DR dirumuskan

$y_{i}(n)=X_{i}\left(n-l_{1}\right), \quad 0 \leq l_{1} \leq L_{1}$

dimana, $L_{1}$ menyatakan jumlah elemen dalam vektor masukan ke-i.

Untuk hidden layer yang mempunyai neuron sebanyak $j$, matrik bobot masukan dan matrik bobot recurrent pada saat $n$ masing-masing dinyatakan sebagai $w_{i j 1_{1}}(n)$ dan $w_{j}(n)$, maka nilai neuron ke-j dirumuskan:

$s_{j}(n)=\left(\sum_{i} \sum_{h_{1}=0}^{L_{1}} w_{i j h}(n) y_{i}(n)\right)+w_{j}(n) y_{j}(n-1)$

dimana $y_{j}(n-1)$ menyatakan koneksi recument dari neuron ke-j dalam hidden layer, dan $y_{j}(0)=0$.

Tiap-tiap neuron dalam hidden layer mempunyai fungsi alih nonlinier. Keluaran dari hidden layer pada saat $n$ dirumuskan

$y_{j}(n)=f\left(s_{j}(n)\right)$

Untuk output layer yang mempunyai neuron sebanyak $k$ dengan fungsi alih linier, matrik bobot keluaran $w_{j k}(n)$, maka keluaran dari output layer dirumuskan

$y_{k}(n)=\sum_{j} w_{j k}(n) y_{j}(n)$

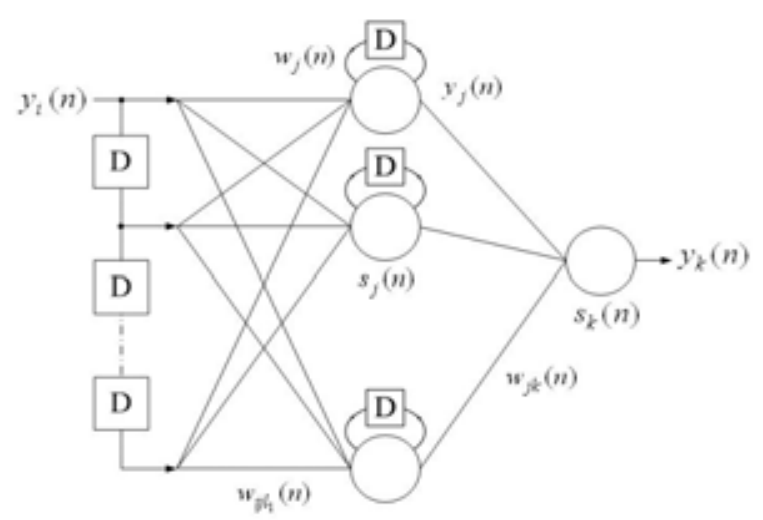

Gambar 7. Struktur JSTDR

\section{METO DE PENELITIAN}

Metoda penelitian yang dilakukan pada penelitian ini adalah:

o Studi literatur yang berhubungan dengan sistem kendali derau akustik secara akt if (Active Noise Control, ANC) dan sistem cerdas.

o Pengembangan algoritma sistem kendali. Algoriritma-algoritma yang dibahasmeliputi: FIR(FX LMS mewakili sistem linier) dan JST Diagonal recurrent (algoritma non-linier)

o Pembuatan program untuk pengambilan data (data primer dan data sekunder)

o Pengambilan data yang dilakukan di Lab. ANC departemen Teknik Elektro ITB.

o Pembuatan program simulasi untuk sistem kendali dan jalur sekunder.

o Analisis hasil simulasi

o Implementasi pada DSP 320C6701 EVM dan perangkat akuisisi data yang tersedia di laboratorium ANC LSKK (Laboratorium Sistem Kendali dan Komputer) ITB.

o Analisis hasil percobaan. 
o Membandingkan kinerja dari masing-masing algoritma.

\section{HASIL DAN PEMBAHASAN}

Implementasi sistem kendali derauaktif dapat dibagi menjadi dua tahap utama, yaitu: prosesidentifikasi jalur sekunder dan proses pengendalian derau secara aktif.

Dalam penelitian ini, struktur yang dignakan baik untuk mengidentifikasi jalur sekunder maupun sebagai pengendali adalah Jaringan Syaraf T inuan Diagonal Recurrent (JST DR). Untuk mengestimasi bobot-bobot JST DR digunakan algoritmaExtended Kalman Filter Diagonal Recurrent (EKFDR).

Tolok ukur kinerja proses identifikasi adalah nilai mean square error (mse) kecil, dan Signal to Emor Ratio (SER) besar. Tolok ukur kinerja proseskendali derau aktif adalah besarnya redaman pada frekuensi derau dan kemampuan untuk mengkompensasi nonlinieritas jalur sekunder pada saat proseskendali (redaman pada frekuensi harmonisa).

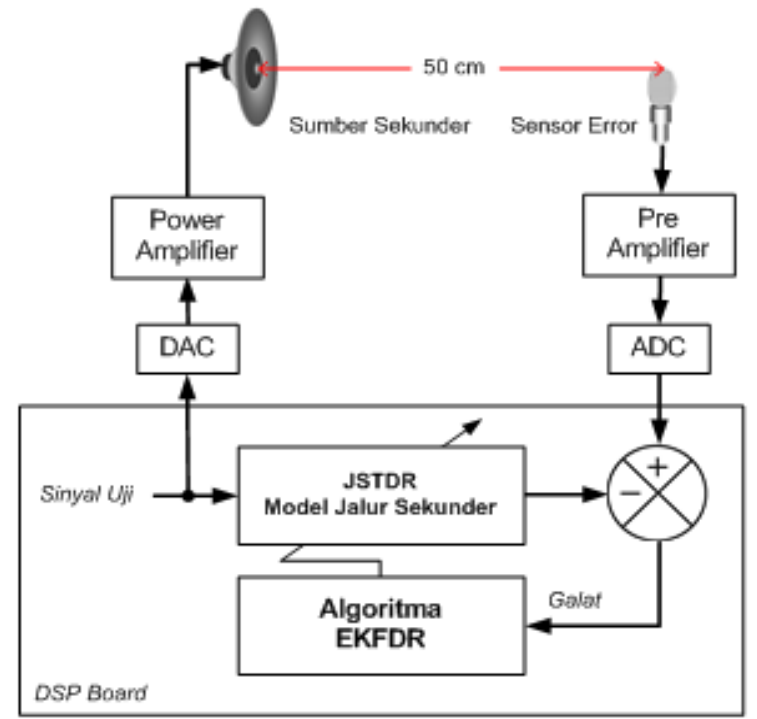

Gambar 8. Konfigurasi percobaan identifikasi jalur sekunder.

Untuk menguji kinerja dari struktur JSTDR(aloritma EKFDR), struktur yang digunakan sebagai pembanding adalah JST umpan maju (algoritma EKF) dan struktur FIR (algoritma LMS). P erbandingan antara JST DR (aloritma EKFDR) dengan struktur JST umpan maju (algoritma EKF), ditinjaudari banyaknya jumlah neuron yang digunakan dalam proses identifikasi jalur sekunder. M menyatakan jumlah input neuron, $\mathbf{N}$ menyat akan jumlah hidden neuron, dan $\mathbf{O}$ menyatakan jumlah output neuron.
Perbandingan antara struktur JSTDR (aloritma EKFDR) dengan struktur FIR (algoritma LMS), ditinjau dari kemampuan untuk mengkompensasi nonlinieritas jalur sekunder pada saat proseskendali. Dalam percobaan ini, frekuensi sinyal eksitasi pada saat proses identifikasi adalah frekuensi derau(125 $\mathrm{Hz}$ ), dan harmonisanya ( $250 \mathrm{~Hz}$ dan $375 \mathrm{~Hz}$ ), dengan frekuensi sampling $2030 \mathrm{~Hz}$. Perangkat yang digunakan dalam implementasi adalah DSP 320C6701 EVM dan perangkat akuisisi data yang tersedia di laboratorium ANC LSKK(Laboratorium Sistem Kendali dan Komputer) ITB.

\section{Identifikasi Jalur Sekunder}

Identifikasi jalur sekunder dilakukan untuk mengkompensasi fungsi transfer dari peralatan-peralatan elektronik yang digunakan dan jalur akustik yang dilewati oleh sinyal derau. Dari hasil identifikasi diperoleh model jalur sekunder yang merupakan media propagasi balik sinyal residu ke jaringan pengendali. Sinyal eksitasi (sinyal uji) yang digunakan adalah sinyal sinusoidal $125 \mathrm{~Hz}$ (frekuensi sinyal derau primer yang akan diredam pada sistem kendali), beserta harmonisanya $(250 \mathrm{~Hz}$ dan $375 \mathrm{~Hz})$.

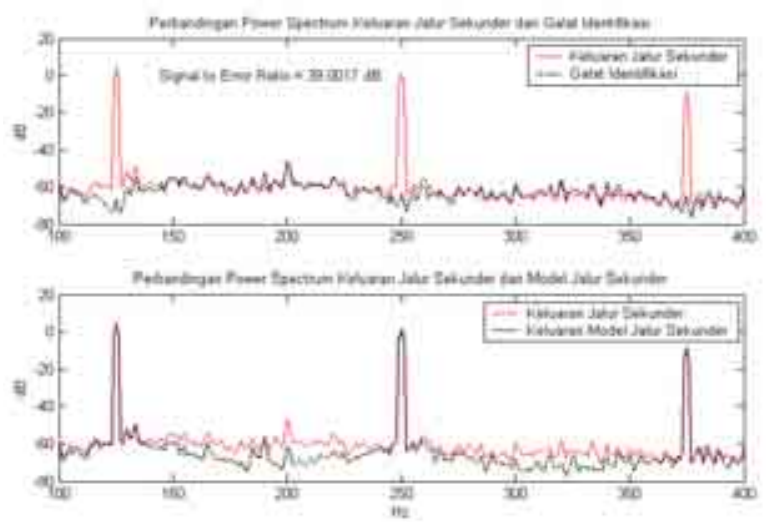

Gambar 9a.Plot power spectrum hasil dentifikasi jalur sekunder menggunakan JST umpan maju $(\mathrm{M}=10, \mathrm{~N}=6, \mathrm{O}=1)$.

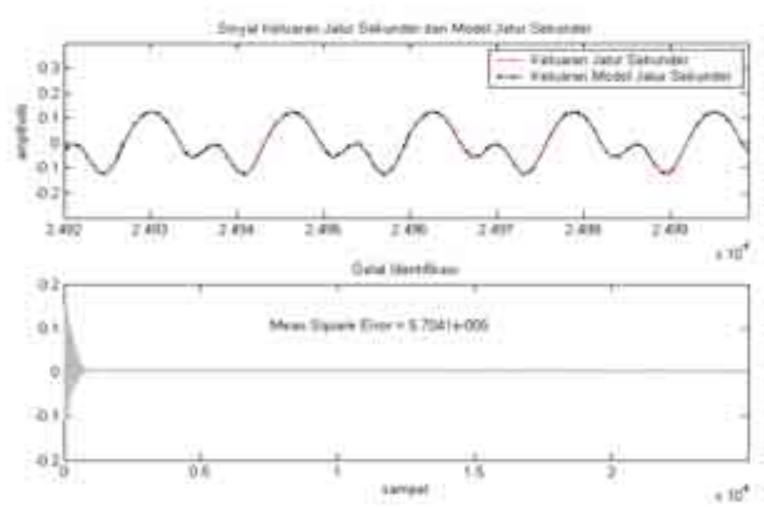

Gambar 9b.Perkembangan sinyal hasil dentifikasi jalur sekunder menggunakan JST umpan maju $(\mathrm{M}=10, \mathrm{~N}=6, \mathrm{O}=1)$. 


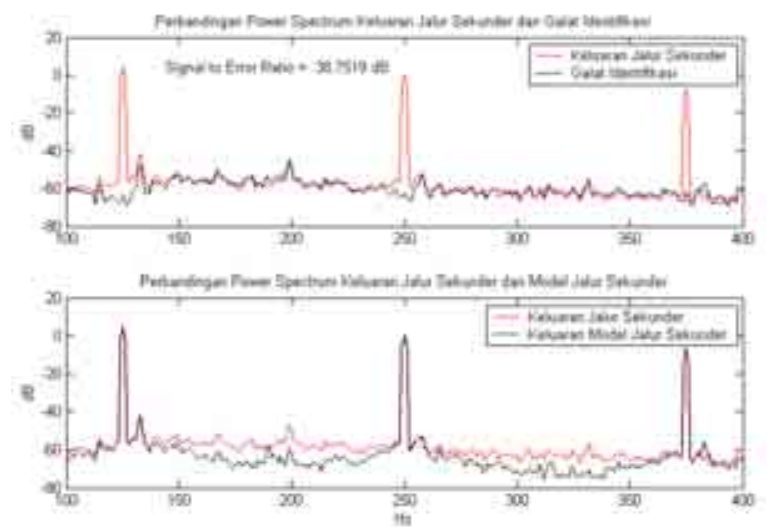

Gambar 10a.Plot power spectrum hasil dentifikasi jalur sekunder menggunakan JSTDR $(\mathrm{M}=10, \mathrm{~N}=2, \mathrm{O}=1)$.

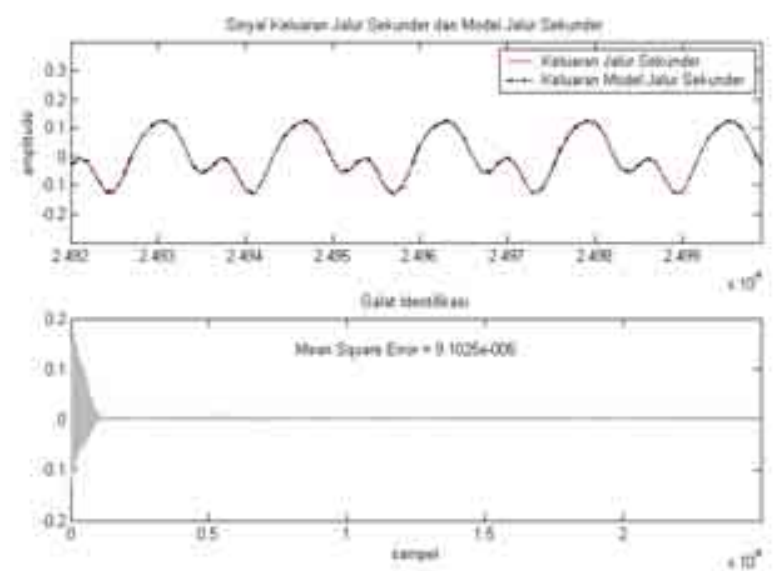

Gambar 10b.Perkembangan sinyal hasilidentifikasi jalur sekunder menggunakan JST DR $(\mathrm{M}=10, \mathrm{~N}=2, \mathrm{O}=1)$.

Tabel 1. Identifikasi jalur sekunder mengginakan JST umpan maju.

\begin{tabular}{ccccc}
\hline \multicolumn{5}{c}{ JST Umpan Maju (EKF) } \\
\cline { 1 - 3 } \multicolumn{1}{c}{ Konfigurasi Neuron } & $\begin{array}{c}\text { Signal to } \\
\text { Error Ratio }\end{array}$ & $\begin{array}{c}\text { Mean Square } \\
\text { Error }\end{array}$ \\
\cline { 1 - 3 } $\mathbf{M}$ & $\mathbf{N}$ & $\mathbf{O}$ & $17.957 \mathrm{~dB}$ & 0.0072 \\
7 & 6 & 1 & $23.256 \mathrm{~dB}$ & 0.0077 \\
8 & 6 & 1 & $32.760 \mathrm{~dB}$ & $9.6595 \mathrm{e}-005$ \\
9 & 6 & 1 & $39.002 \mathrm{~dB}$ & $5.7041 \mathrm{e}-005$ \\
10 & 6 & 1 & &
\end{tabular}

Tolok ukur keberhasilan identifikasi jahr sekunder ditunjukkan dengan menghitung Signal to Error Ratio (SER), yaitu dengan menganggap sinyal keluaran jalur sekunder sebagai sinyal yang diinginkan dan galat identifikasi pada saat steady state (tunak) sebagai sinyal error. Signal to EmorRatio (SER) dirumuskan

$S E R=10(\log 10(\operatorname{var}(s(n)))-\log 10(\operatorname{var}(e(n))))$.

dimana:

$s(n)=$ sinyal yang diinginkan.

$e(n)=$ sinyal error .
Konfigurasi percobaan untuk identifikasi jalur sekunder diperlihatkan dalam Gambar 8.

\section{Identifikasi Jalur Sekunder Menggunakan JST Umpan Maju}

Salah satu plot data hasil percobaan identifikasi jalur sekunder menggunakan JST umpan maju(algoritma EKF), diperlihatkan pada Gambar 9.a. dan 9.b. Data hasil percobaan identifikasi jalur sekunder meng gunakan JST umpan maju (algoritma EKF) dirangkum dalam Tabel 1.

\section{Identifikasi Jalur Sekunder Menggunakan JSTDR}

Salah satu plot data hasil percobaan identifikasi jalur sekunder menggunakan JSTDR(algoritma EKFDR), diperlihatkan pada Gambar 10.a dan 10.b. Data hasil percobaan identifikasi jalur sekunder menggunakan JST umpan maju (algoritma EKF) dan JSTDR (algoritma EKFDR) dirangkum dalam Tabel 2.

Tabel 2. Perbandingan antara JST umpan majudan JST DR dalam identifikasi jalur sekunder.

\begin{tabular}{|c|c|c|c|c|}
\hline \multicolumn{5}{|c|}{ JST Umpan Maju (EKF) } \\
\hline \multicolumn{3}{|c|}{$\begin{array}{l}\text { Konfigurasi } \\
\text { Neuron }\end{array}$} & \multirow{2}{*}{$\begin{array}{c}\text { Signal to Error } \\
\text { Ratio }\end{array}$} & \multirow{2}{*}{$\begin{array}{c}\text { Mean Square } \\
\text { Error }\end{array}$} \\
\hline $\mathbf{M}$ & $\mathbf{N}$ & $\mathbf{O}$ & & \\
\hline 7 & 6 & 1 & $17.9574 \mathrm{~dB}$ & 0.0072 \\
\hline 8 & 6 & 1 & $23.2565 \mathrm{~dB}$ & 0.0077 \\
\hline 9 & 6 & 1 & $32.7605 \mathrm{~dB}$ & $9.6595 e-005$ \\
\hline 10 & 6 & 1 & $39.0017 \mathrm{~dB}$ & $5.7041 \mathrm{e}-005$ \\
\hline \multicolumn{5}{|c|}{ JST Diagonal Recurrent (EKFDR) } \\
\hline 8 & 2 & 1 & $33.3415 \mathrm{~dB}$ & $2.8098 \mathrm{e}-004$ \\
\hline 9 & 2 & 1 & $37.6240 \mathrm{~dB}$ & $1.5541 \mathrm{e}-004$ \\
\hline 10 & 2 & 1 & $38.7519 \mathrm{~dB}$ & $9.1025 \mathrm{e}-005$ \\
\hline
\end{tabular}

Dari Tabel 2, dengan tinjauan konfigurasi neuron, terlihat bahwa untuk mencapai nilai Signal to Error dan Mean Square Error yang sebanding JST umpan maju (algoritma EKF) memerlukan jumlah neuron yang lebih banyak jika dibandingkan dengan JSTDR (algoritma EKFDR).

Dapat disimpulkan bahwa dengan menggunakan JST DR, jumlah neuron yang digmakan menjadi lebih sedikit. Sehingga diharapkan dapat mengurangi beban komputasi.

\section{Sistem Kendali Derau Aktif}

Sinyal derau yang digunakan mempunyai frekuensi $125 \mathrm{~Hz}$. Frekuensi sampling yang digunakan adalah $2030 \mathrm{~Hz}$. Kinerja pengendali dalam meredam sinyal derau, dilihat dari peredaman yang diperoleh pada frekuensi sinyal derau $(125 \mathrm{~Hz})$. Dengan menganggap bahwa sinyal disturbance sebagai sinyal deraudan 
sinyal error sebagai sinyal residu, redaman dirumuskan:

Redaman $=10(\log 10(\operatorname{var}(d(n)))-\log 10(\operatorname{var}(e(n))))$

dimana:

$d(n)=$ sinyal disturbance, dan

$e(n)=$ sinyal error .

Kinerja pengendali dalam mengkompensasi nonlinierit as jalur sekunder, dilihat dariperedaman yang diperoleh pada frekuensi harmonisa yangdihasilkan oleh sumber sekunder $(250 \mathrm{~Hz}$ dan $375 \mathrm{~Hz}$ ). Nonlinieritas jalur sekunder (media yang dilewati oleh sinyal derau) ditandai dengan timbulnya frekuensi harmonisa pada sinyal keluaran jalur sekunder.

\section{Sistem kendali derau aktif menggunakan JSTDR}

Konfigurasi percobaan untuk sistem kendali derau aktif diperlihatkan dalam Gambar 11.

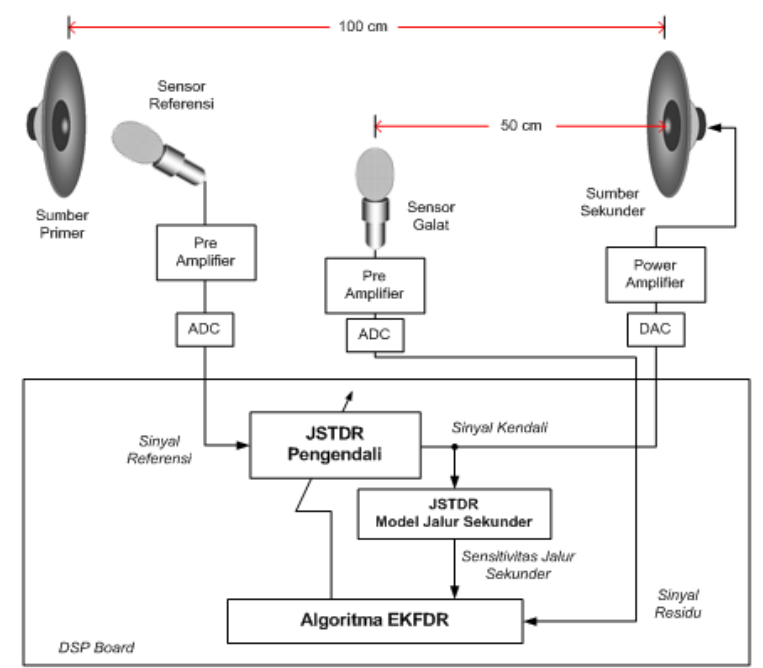

Gambar 11.Konfigurasi percobaan sistem kendali derau aktif.

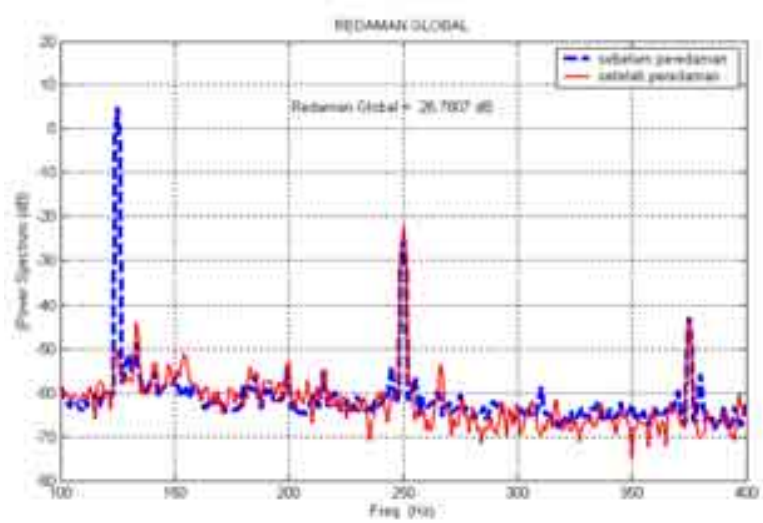

Gambar 12a. Plot power spectrum sinyal residu $(\mathrm{M}=6, \mathrm{~N}=4, \mathrm{O}=1)$.
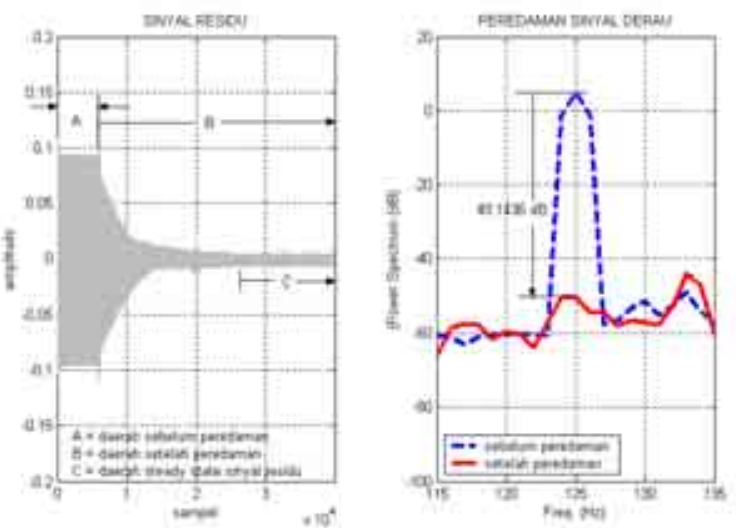

Gambar 12b.Perkembangan dan plot power spectrum sinyal residu $(\mathrm{M}=6, \mathrm{~N}=4, \mathrm{O}=1)$.

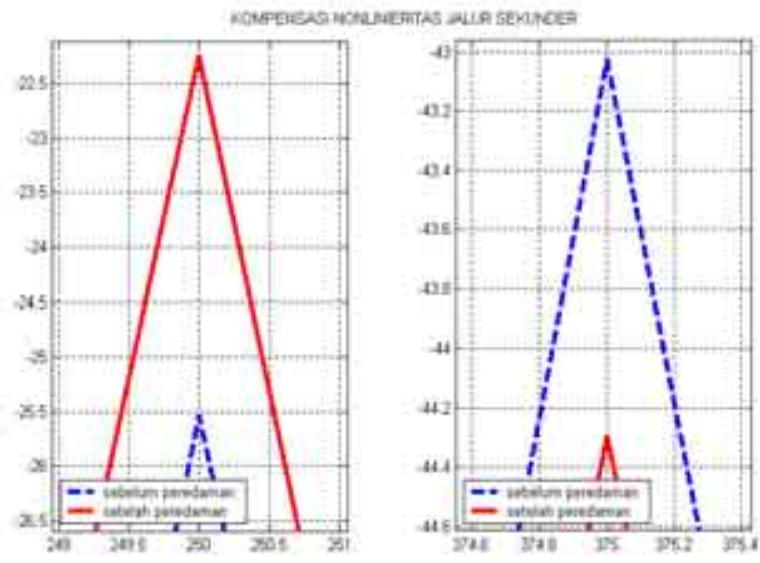

Gambar 12c.P lot power spectrum sinyal residupada frek. harmonisa $(\mathrm{M}=6, \mathrm{~N}=4, \mathrm{O}=1)$.

Salah satu plot data hasil percobaan sistem kendali derau aktif menggunakan JSTDR dengan algoritma EKFDR (konfigurasi neuron: $\mathrm{M}=6, \mathrm{~N}=4, \mathrm{O}=1$ ), diperlihatkan pada Gambar 12.a. - 12.c.

JST DR (konfigurasi neuron: $\mathrm{M}=6, \mathrm{~N}=4, \mathrm{O}=1$ ), berhasil meredam sinyal derau (pada frekuensi 125 $\mathrm{Hz}$ ) sebesar 49.1436 dB. Kompensasi terhadap nonlinieritas jalur sekunder; pada frekuensi harmonisa $250 \mathrm{~Hz}$ power spectrum sinyal residu mengalami peningkatan sebesar $3.5049 \mathrm{~dB}$, pada frekuensi harmonisa $375 \mathrm{~Hz}$ terjadi peredaman sebesar 0.8319 $\mathrm{dB}$, dan redaman global sebesar $26.7807 \mathrm{~dB}$. Rangkuman data hasil percobaan implementasi sistem kendali derau aktif menggunakan pengendali JST DR (algoritma FX-EKFDR) padaruangterbuka disusun dalam Tabel 3.

Dari tabel 3. secara umum dapat disimpulkan bahwa dengan menambah jumlah neuron, dapat meningkatkan kinerja pengendali JSTDR, baik dalam meredam derau maupun mengkompensasi nonlinieritas jalur sekunder. Penambahan inputneuron, 
berdampak pada peningkatan kemampuan pengendali dalam meredam derau. Penambahan hidden neuron, berdampak pada peningkatan kemampuan pengendali dalam mengkompensasi nonlinieritas jalur sekunder.

Tabel 3. Rangkuman Data Hasil Percobaan Implementasi Sistem ANC menggunakan JSTDR (algoritma EKFDR).

\begin{tabular}{ccccccc}
\hline \multicolumn{6}{c}{ JSTDR (algoritma EKFDR) } \\
\hline $\begin{array}{c}\text { Konf igurasi } \\
\text { Neuron }\end{array}$ & \multicolumn{5}{c}{ REDAMAN (dB) } \\
\hline $\mathbf{M}$ & $\mathbf{N}$ & $\mathbf{O}$ & $\mathbf{1 2 5} \mathbf{~ H z}$ & $\mathbf{2 5 0 ~ H z}$ & $\mathbf{3 7 5} \mathbf{~ H z}$ & GLOB AL \\
\hline 2 & 12 & 1 & 20.0599 & 4.7414 & 0.2015 & 16.6802 \\
& & & & & & \\
4 & 12 & 1 & 31.5207 & 5.7817 & 0.5906 & 19.9718 \\
& & & & & & \\
6 & 4 & 1 & 49.1436 & -3.5049 & 0.8319 & 26.7807 \\
6 & 6 & 1 & 50.6110 & -2.8119 & 1.6977 & 27.1518 \\
6 & 8 & 1 & 53.3589 & -2.6567 & 3.2630 & 27.5703 \\
& & & & & & \\
8 & 4 & 1 & 49.4639 & -3.1603 & 4.9296 & 27.4074 \\
8 & 6 & 1 & 52.6825 & -2.7709 & 5.4035 & 27.2758 \\
8 & 8 & 1 & 53.8102 & -2.6506 & 2.5662 & 27.3794 \\
& & & & & & \\
10 & 4 & 1 & 55.6969 & -2.9851 & 3.2684 & 27.3603 \\
10 & 6 & 1 & 55.8448 & -2.8379 & 2.5983 & 27.3254 \\
10 & 8 & 1 & 56.7602 & -2.7525 & 3.2055 & 27.2251 \\
\hline
\end{tabular}

\section{Perbandingan Kinerja Filter FIRdan JSTDR}

Pengendali linier yang digunakan sebagai pembanding dalam mengkompensasi nonlinieritas jalur sekunder adalah filter FIR (algoritma FX-LMS), dengan jumlah koefisien sebanyak 80. Dalam penelitian ini tidak dibahas mengenai filter FIR dan algoritma FX-LMS. Untuk pengambilan data pembanding, digunakan filter FIRdan algoritma FXLMS dari dokumentasi yang sudah tersedia di laboratorium ANC LSKK ITB. Dari hasil percobaan menggunakan filter FIR (algoritma FX-LMS) diambil data yang dianggap paling baik, dengan tinjauan redaman pada frekuensi derau dan pada frekuensi harmonisa.

Filter FIR (jumlah koefisien $=80$ ) dengan algoritma FX-LMS, berhasil meredam sinyal derau $(125 \mathrm{~Hz})$ sebesar $53.6824 \mathrm{~dB}$. Kompensasi terhadap nonlinierit as jalur sekunder; pada frekuensi harmonisa $250 \mathrm{~Hz}$ power spectrum sinyal residu mengalami peningkatan sebesar $8.8551 \mathrm{~dB}$, pada frekuensi harmonisa $375 \mathrm{~Hz}$ mengalami peningkatan sebesar $3.891 \mathrm{~dB}$, dan redaman global sebesar $24.5821 \mathrm{~dB}$.

Dari semua data hasil percobaan terlihat bahwa baik pengendali FIR (algoritma FX-LMS) maupun JST DR (algoritma FX-EKFDR) dapat meredam sinyal derau secara signifikan.
Nonlinieritas sumber sekunder yang ditandai dengan munculnya harmonisa pada $250 \mathrm{~Hz}$ dan $375 \mathrm{~Hz}$, pengendali JSTDR menunjukkan kinerja yanglebih baik dari Filter FIR (dengan peningkatan redaman berkisar antara 5,3502 dB sampai 14,6369 dBpada frekuensi $250 \mathrm{~Hz}$, dan $4.0910 \mathrm{~dB}$ sampai $9.2945 \mathrm{~dB}$ pada frekuensi $375 \mathrm{~Hz}$ ).

Tabel 4. Rangkuman Data Hasil Percobaan Implementasi Sistem ANC menggunakan Filter FIR (algoritma FX-LMS).

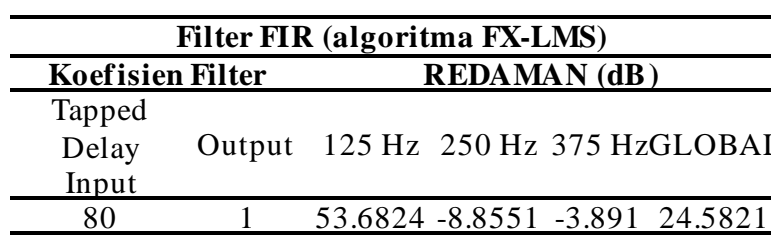

\section{KES IMPULAN}

Berdasarkan data hasil percobaan implementasi sistem kendali derau aktif pada ruang terbuka mengunakan JST DR (algoritma EKFDR), dapat disusun kesimpulan sebagai berikut:

1. Penggunaan struktur JST DR dapat mengurangi jumlah neuron dalam struktur JST.

2. Penambahan input neuron berdampak pada peningkatan kinerja dalam hal pencapaian redaman pada frekuensi derau.

3. Penambahan hidden neuron berdampak pada peningkatan kinerja dalam halmengkompensasi nonlinieritas jalur sekunder.

4. Pengendali JST DR (algoritma EKFDR), memperlihatkan kinerja yang lebih baik dalam mengkompensasi nonlinieritas jalur sekunder jika dibandingkan dengan pengendali linier.

\section{DAFTAR PUSTKA}

[1] S. M. Kuo and D. R. Morgan, Active Noise Control Systems: Algorithms and DSP Implementations. New York: Wiley, 1996.

[2] M. Bouchard, B. Paillard, and C. T. Le Dinh, "Improved Training of Neural Networks for Nonlinear Active Control of Noise and Vibration”, IEEE Trans. Neural Networks, vol. 10, 1999, pp. 391-401

[3] M. Bouchard, "New Recursive-Least-Squares Algorithms for Nonlinear Active Control of Sound and Vibration using Neural Networks", IEEE Trans. Neural Networks, vol. 12, 2001, pp. 135-147

[4] S. J. Elliot, Signal Processing for Active Control. Academic Press, 2001. 
[5] S. M. Kuo and D. R. Morgan, "Active Noise Control Systems: A Tutorial Review”. IEEE Trans. Neural Networks, vol. 87, 1999, pp. 943971.

[6] C. C. Ku and K. Y. Lee, “Diagonal Recurrent Neural Networks for Dynamic Systems Control”, IEEE Trans. Neural Networks, vol. 6, 1995, pp. 144-155.

[7] S. D. Snyder and N. Tanaka, "Active Control of Vibration using a Neural Network", IEEE Trans. Neural Networks, vol.6, 1995, pp. 819830.

[8] Simon Haykin, Neural Networks, Prentice Hall, New Jersey, 1999.

[9] Jang, J.-S. R., C.-T. Sun, and E Mizzutami. Neuro-Fuzzy and Soft Computing. Prentice Hall Inc., 1997.

[10] Jang, J.-S. R. and C.-T. Sun. “Neuro-Fuzzy Modeling and Control”. Proceedings of the IEEE, March 1995. 